Advance Journal of Food Science and Technology 16(SPL): 273-279, 2018

DOI:10.19026/ajfst.16.5967

ISSN: 2042-4868; e-ISSN: 2042-4876

(C) 2018 Maxwell Scientific Publication Corp.

Submitted: September 14, 2017

Accepted: December 26, 2017

Published: November 10, 2018

\title{
Research Article \\ Quinoa and Amaranth as Protein Source in the Elaboration of a Cooked Ham-Type Meat Analog
}

\author{
${ }^{1,2}$ Ángela García Salcedo, ${ }^{1}$ Olga Lucía Torres Vargas and ${ }^{1,2}$ Kelly Figueroa López \\ ${ }^{1}$ Grupo de Investigación en Ciencias Agroindustriales, \\ ${ }^{2}$ Optoelectronics Group, Interdisciplinary Science Institute, Universidad del Quindío, \\ Carrera 15 Calle 12 Norte Armenia, Quindío, Colombia
}

\begin{abstract}
The aim of the research was to obtain a meat analog by using a flour mixture composed of quinoa and amaranthas protein source of plant origin. For this purpose, an optimal mixture was formulated of flours composed of quinoa and amaranth, which was texturized in an extruder to form an emulsion. To optimize the emulsion, the study used a response surface central composite design. The input factors were percentage of mixture, percentage of humidity and percentage of oil and the response variable considered the percentage of protein in the mixtures. The results indicated that the optimal emulsion consisted of 55/100 g of humidity, 3/100 g of oil, 42/100 $\mathrm{g}$ of flour mixture and 18/100 g of protein. The optimal mixture showed appropriate viscous-elastic behavior to prepare a cooked ham-type meat analog. The analog obtained complied with the physical-chemical parameters of texture and color established by NTC 1325 .
\end{abstract}

Keywords: Color, emulsion, response surfaces, texture, texturized flours

\section{INTRODUCTION}

Historically, meat has been the principal protein source of animal origin, understanding by meat the whole pieces or ground tissue with a significant protein content, as well as triglycerides, phospholipids and carbohydrates. However, a trend exists to diminish its consumption and production due to ethical preferences and environmental factors that have evidenced the generation of greenhouse gases, erosion, affectation of hydric sources, etc., (Aiking, 2011). These factors do not compensate the yield obtained by the proteins from plant origin sources. In addition, if we consider the increased global population, meat consumption becomes a non-sustainable practice.

Individual vegetable sources do not provide all the essential amino acids. Through their combinations, complete protein intake may be obtained, known as composite flours (mix of cereals, legumes, pseudocereals), which constitute an innovative source to manufacture balanced foods (Ayodele and Aladesanmi, 2013).

Conversion of vegetable-source proteins in to products that imitate the texture of meat is one of the big innovations of the food industry. Meat analogs are formulated with proteins of plant origin; they are gluten free and use their own starch and fiber to form the emulsion. Currently, vegetables, like greens, grains, seeds and proteins derived from mush rooms are used to elaborate meat analogs, with the most used being emulsions of cooked vegetables (smooth) and texturized vegetable protein (fibrous) (Rumpold and Schlüter, 2013).

Quinoa (Chenopodium quinoa) and amaranth (Amaranthus caudatus) are promissory alternatives to substitute animal protein, given the high content of protein and fiber, the nutritional and differential balance with respect to cereals and legumes (Repo-Carrasco et al., 2003). The lack of sufficient protein in nutrition has stirred interest for the use of these endogenous crops from Andean regions, which have exceptional functional and nutritional properties to substitute and imitate animal protein (Sandoval-Oliveros and ParedesLopez, 2013).

Extrusion is a unique food processing operation, which uses High Temperature, Short Time (HTST) and high shear force to produce a product with distinct physical and chemical characteristics (Filli et al., 2010). The process implies subjecting the food material to cooking through a single screw, or a set of screws, enclosed in a barrel. The food is forced through a die where the product is formed (Omeire et al., 2013). In this process, through combination of humidity, pressure, temperature and mechanical shearing, the

\footnotetext{
Corresponding Author: Olga Lucía Torres Vargas, Grupo de Investigación en Ciencias Agroindustriales, Universidad del Quindío, Carrera 15 Calle 12 Norte Armenia, Quindío, Colombia

This work is licensed under a Creative Commons Attribution 4.0 International License (URL: http://creativecommons.org/licenses/by/4.0/).
} 
Adv. J. Food Sci. Technol., 16(SPL): 273-279, 2018

product undergoes transformations at molecular level, increasing its viscoelastic properties and digestibility of nutrients (Juansang et al., 2012). Hence, this research used extrusion to texturize and increase the availability of proteins in the flour comprised of quinoa and amaranth to obtain a cooked ham-type meat analog.

\section{MATERIALS AND METHODS}

Raw matter: Quinoa (Chenopodium quinoa) and Amaranth (Amaranthus caudatus) flours, complying with NTC 267, were acquired at a local market in the city of Armenia (Quindío). The research was conducted in the Food Laboratory of the Interdisciplinary Sciences Institute at Universidad del Quindío.

Experimental design: An experimental Box-Behnken design was used through the response surface methodology, with three independent factors: Percentage of flour in each mixture, percentage of hydration $(55-70 \%)$, percentage of oil (3-7\%) and a response variable (percentage of protein). The design generated 15 combinations of factors. The optimized design was statistically analyzed through Analysis of Variance (ANOVA) with $\mathrm{p}<0.05$. The percentage of each flour in the mixture was predetermined for its identification in the Statgraphics Centurion XVI software (Table 1).

The regression analysis was solved with a secondorder polynomial model, according to Eq. (1):

$$
\mathrm{Y}=\mathrm{b}_{0}+\sum_{\mathrm{i}=1}^{\mathrm{k}} \mathrm{b}_{\mathrm{i}} \mathrm{x}_{\mathrm{i}}+\sum_{\mathrm{i}=1}^{\mathrm{k}} \mathrm{b}_{\mathrm{ii}} \mathrm{X}_{\mathrm{i}}^{2}+\sum_{\mathrm{i}=1}^{\mathrm{k}-1} \sum_{\mathrm{j}=2}^{\mathrm{k}} \mathrm{b}_{\mathrm{ij}} \mathrm{X}_{\mathrm{i}} \mathrm{X}_{\mathrm{j}}
$$

where,

$\beta_{\mathrm{i}} \quad=$ The fit constants of the statistical model

$\mathrm{X}_{\mathrm{i}}=$ The model statistical factors $(\mathrm{A}=$ percentage of flour in the mixture

$\mathrm{B}=$ Percentage of hydration

$\mathrm{C}=$ Percentage of oil)

$\mathrm{k}=$ The number of factors of the model (Asare et al., 2010)

Extrusion: For the purpose of homogenizing, texturizing and increasing the bioavailability of proteins fifteen emulsions were prepared according to the combination of factors, these were subjected to an extrusion process. For this purpose, a locally manufactured extruder was used, with a helicoid solid screw measuring $80 \mathrm{~cm}$ with 3 -inch diameter, with an operational capacity between 1 and $150 \mathrm{~kg} / \mathrm{h}$; with forced transmission through $2-\mathrm{Hp} 220-\mathrm{V}$ monophasic gear motor and variable speed drive between 0 and 60 rpm, cylinder heating system through electrical resistance clamp from $1.4 \mathrm{~kW}-220 \mathrm{~V}$, operated by a PID temperature electronic control with temperature range of $70-73^{\circ} \mathrm{C}$.

Rheology: A controlled-stress rheometer (Anton Paar series MCR 301) was used, equipped with a
Table 1: Percentage of flour in each mixture

\begin{tabular}{llll}
\hline Flour & Mixture 1 (\%) & Mixture 2 (\%) & Mixture 3 (\%) \\
\hline Quinoa & 50 & 30 & 70 \\
Amaranth & 50 & 70 & 30 \\
\hline
\end{tabular}

Table 2: Combination of factors yielded by the experimental design with the respective protein percentage

\begin{tabular}{lllll}
\hline Emulsions & Mixture & Humidity $(\%)$ & Oil $(\%)$ & Protein $(\%)$ \\
\hline 1 & 1 & 70.00 & 5 & 12.89 \\
2 & 3 & 70.00 & 5 & 15.00 \\
3 & 2 & 55.00 & 7 & 14.68 \\
4 & 2 & 62.50 & 5 & 12.21 \\
5 & 2 & 62.50 & 5 & 12.22 \\
6 & 3 & 70.00 & 3 & 14.06 \\
7 & 1 & 62.50 & 3 & 17.81 \\
8 & 3 & 62.50 & 3 & 14.24 \\
9 & 2 & 70.00 & 7 & 10.05 \\
10 & 2 & 55.00 & 5 & 16.23 \\
11 & 1 & 62.50 & 7 & 13.70 \\
12 & 3 & 62.50 & 7 & 12.24 \\
13 & 1 & 55.00 & 5 & 17.06 \\
14 & 2 & 62.50 & 5 & 12.23 \\
15 & 2 & 55.00 & 3 & 13.80 \\
EOP & 1 & 55.00 & 3 & 18.30 \\
\hline
\end{tabular}

CC27/T200/SS concentric cylinder system, a 1-mm GAP and parallel plates (diameter of the upper plate 25 $\mathrm{mm}$ ). The experiments were carried out at $25^{\circ} \mathrm{C} \pm 0.1$, controlled by an external thermostatic liquid bath unit. The storage module $\left(G^{\prime}\right)$ and the loss module $\left(G^{\prime \prime}\right)$ were determined in a frequency range between 0.1 and 100 $\mathrm{Hz}$.

The rheological behavior was modelled with power law Eq. (2):

$$
\tau=\mathrm{k} \dot{\gamma}^{\mathrm{n}}
$$

where,

$\tau=$ Strain $(\mathrm{Pa})$

$\mathrm{k}=$ Consistence index

$\mathrm{n}=$ Behavior index

$\dot{\gamma}=$ Shear rate $(1 / \mathrm{sec})$

It is known that the parameter $\mathrm{n}$ (flow behavior index) can take the value of $n<1, n=1$ and $n>1$. If $n=$ 1 , the material measured is said to be Newtonian. If $\mathrm{n}<1$ then the material is a pseudo-plastic and shear thinning, its viscosity decreases with shear stress. If $\mathrm{n}>1$, the behavior of the fluid is rheopectic and its viscosity increases with shear stress.

Protein: Protein analysis was determined by the Kjeldhal's method, it was used a Büchi K-424 digester and a semi-automatic distiller (Büchi K-350). Official International analysis method (AOAC, 1995). To convert nitrogen into raw, the 6.25 factor is used.

Formulation of the analog: The formulation was standardized to achieve a physical appearance and flavor similar to that of a ham obtained with animal protein (Omohimi et al., 2014). This was done by varying the concentration of spices, flavorings and additives, having $1 \mathrm{k}$ of emulsion as calculation base. Ten formulations were obtained from the Optimized Emulsion (EOP) (Table 2). 
Adv. J. Food Sci. Technol., 16(SPL): 273-279, 2018

Table 3: Composition of the Optimal Emulsion (EOP) obtained through response surface design

\begin{tabular}{llll}
\hline Factor & Low & High & Optimal \\
\hline Mixture & 1.0 & 3.0 & 1.00 \\
Humidity (\%) & 55.0 & 70.0 & 55.00 \\
Oil (\%) & 3.0 & 7.0 & 3.00 \\
\hline
\end{tabular}

\section{Physical-chemical characterization:}

Color: The instrumental color measurements were carried out in a Hunter Lab spectrocolorimeter (ColorQuest XE) with standard D65 illuminant and $2^{\circ}$ observer in the CIE (Commission Internationale de l'Éclairage [CIE], 1976)-LAB: L*, a* and b* space. The color measurements were performed on the formulations (ATJ), Commercial Ham-Type Analog (ATJC) and Commercial Cooked Ham (JCC). Eight measurements were made in internal sections for each sample and averaged to obtain the final value of each parameter.

Texture: The instrumental Texture Profile (TPA) was obtained from the formulations (ATJ), Commercial Ham-Type Analog (ATJC) and Commercial Cooked Ham (JCC), using a universal TA-XT2 ${ }^{\circledR}$ press (Stable Micro Systems, Godalming, Surrey, UK) and by applying uniaxial compression in two cycles with 5-sec interval until $50 \%$ deformation with the SMS P/75 probeat a rate of $10 \mathrm{~mm} / \mathrm{sec}$ on samples $1 \times 1 \times 2.5 \mathrm{~cm}$ (height $\times$ width $\times$ length). Hardness $(\mathrm{N})$, adhesiveness, cohesion, elasticity, gumminess and chewiness $(\mathrm{N} \times \mathrm{mm})$ were obtained by using the Texture Exponent 32 software v 1.0 (Stable Micro Systems).

Scanning Electron Microscopy (SEM): The emulsions were dehydrated in a forced convection oven and stored in a desiccator until measurements were taken. The images were obtained from Scanning Electron Microscopy (SEM) (JSM-6610LV, JEOL Ltd., Japan). The samples were mounted on aluminum stubs and then coated with gold: palladium $(60: 40)$ in an Edwards S150 sputter coater. The samples were systematically observed with $5000 \mathrm{X}$ magnification.

Statistical analysis: The values obtained from the analyses of color and texture were carried out in triplicate and the mean values were reported with the standard deviation. The $3^{2}$ factorial design was employed by using an analysis of variance to determine the interaction between the factors and the variables by using the Statgraphics Centurion XVI program. Differences were considered significant with $\mathrm{p}<0.05$.

\section{RESULTS AND DISCUSSION}

Optimization of the experimental design: The emulsions prepared according to the combination of factors yielded by the experimental design with their respective protein percentage are presented in Table 2. This table shows that the combination of factors obtaining the highest protein value was emulsion 7, formulated with mixture 1, with a value of $17.81 \%$.

Optimization of the response surface experimental design (Fig. 1) indicated that if we combine the factors of mixture, percentage of humidity and percentage of oil, as described in Table 3, a maximum protein of $18.24 \%$ is obtained, which was corroborated experimentally, as noted in the Optimized Emulsion (EOP) from Table 2.

Hence, the optimal parameters to obtain an emulsion with $18.24 \%$ protein are: $55.0 \%$ humidity, $3 \%$ oil and $42 \%$ flour mix 1 (Table 1), which corresponds to $50 \%$ quinoa flour, $50 \%$ amaranth flour, extruded at $73^{\circ} \mathrm{C}$. Figure 1 shows a graphic representation of the response surface design optimized to the maximum of the percentage of protein with respect to the percentage factors of each flour in the mixture, percentage of oil, percentage of humidity.

The ANOVA of the response surface model to optimize the percentage of protein indicated that the percentage of oil, percentage of humidity and the mixture-mixture interactions showed statistically significant differences, directly influencing upon the protein content of the emulsions. The $\mathrm{R}$ squared value indicates that the adjusted model explains $89.59 \%$ of the protein variability. The optimized emulsion is within the range of protein supplied by commercial meat analogs and meat products, as reported in prior studies (García-Salcedo, 2016). Likewise, it is noted that the $50-50 \%$ quinoa and amaranth mixture (Table 1) potentiates the protein content in the emulsion.

Rheology: Figure 2 and 3 show the viscous-elastic properties of the emulsions formulated through the experimental design at a scan frequency between 0.1 and $100 \mathrm{~Hz}$. The figures demonstrate that the $\mathrm{G}^{\prime}$ storage module was greater than the G" loss module and show how both modules increase exponentially with increased frequency for all the emulsions analyzed. This behavior indicates that the emulsions formulated have a homogeneous structure, besides having a more elastic feature tan viscous (Omeire et al., 2013). These results indicate that emulsions with $55 \%$ water content had the best viscous-elastic behavior because they have higher $G^{\prime}$ values. Hence, the optimal sample also has good rheological behavior.

Using power law Eq. (2), the viscosity behavior of the Optimized Emulsion (EOP) was modeled from the quinoa and amaranth flour. The following was the general Eq. (3):

$$
\log \eta=\log K+(n-1) \log \dot{\gamma}
$$




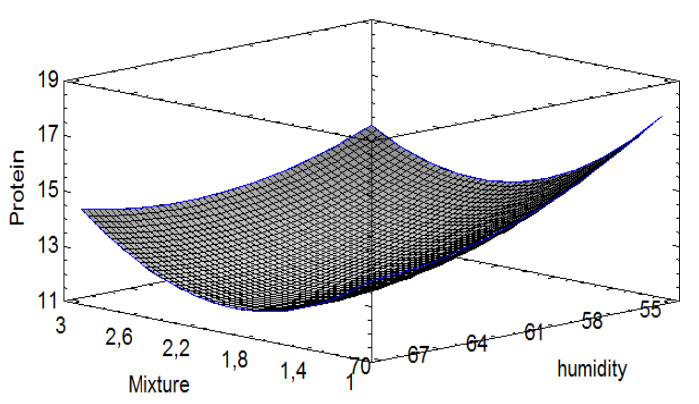

(a)

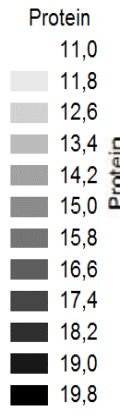

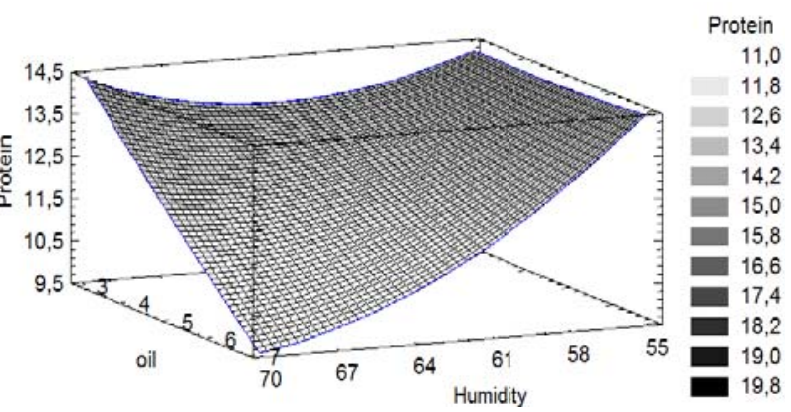

(b)

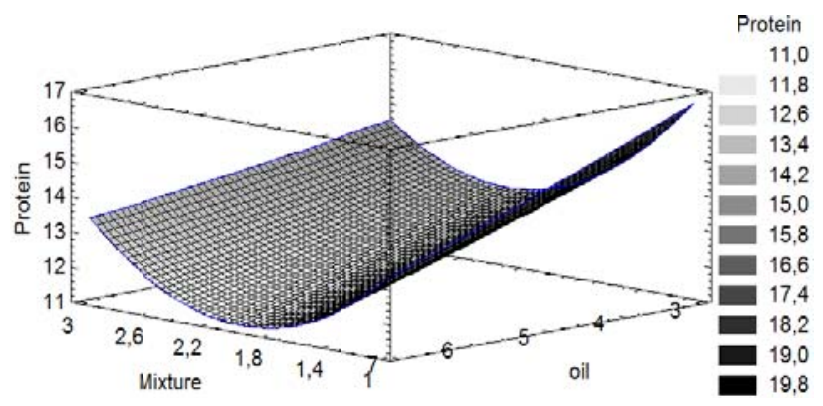

(c)

Fig. 1: Protein response surface against (a) Factor percentage mixture-percentage humidity, (b) Factor percentage oil-percentage humidity, factor percentage mixture-percentage oil

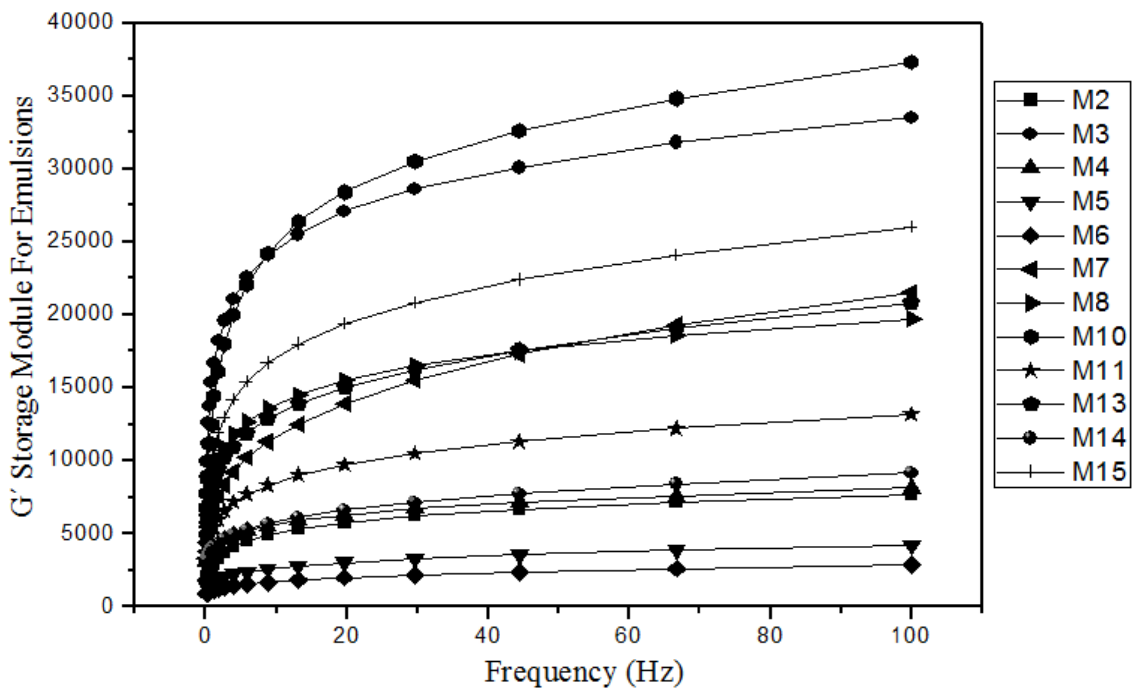

Fig. 2: G' storage module for emulsions formulated with quinoa and amaranth flours

The $\mathrm{R}$ squared for this model was 0.93 . The $\mathrm{n}$ index found in this model shows that the emulsions are within the category of pseudo-plastic materials and had a thinning effect through shearing, $\mathrm{n}<1$. The model obtained in this research (4) can be used to predict the viscosity behavior of the emulsions. Figure 4 shows the $\log$ complex viscosity against the log shear rate assessed experimentally (Contreras-Jiménez et al., 2017) reported similar values for extruded corn mass:

$$
\log \eta=\log 0.89+(-0.75) \log \dot{\gamma}
$$

Formulation: Upon determining that the EOP also had good rheological behavior, the spices and additives necessary to imitate ham were varied (ham flavor, paprika, garlic, nutmeg, smoke, preservative and textured soy), which were integrated onto the emulsion until homogenized for its subsequent pressing and slicing (Fig. 5). Ten Ham-Type Analog (ATJ) 


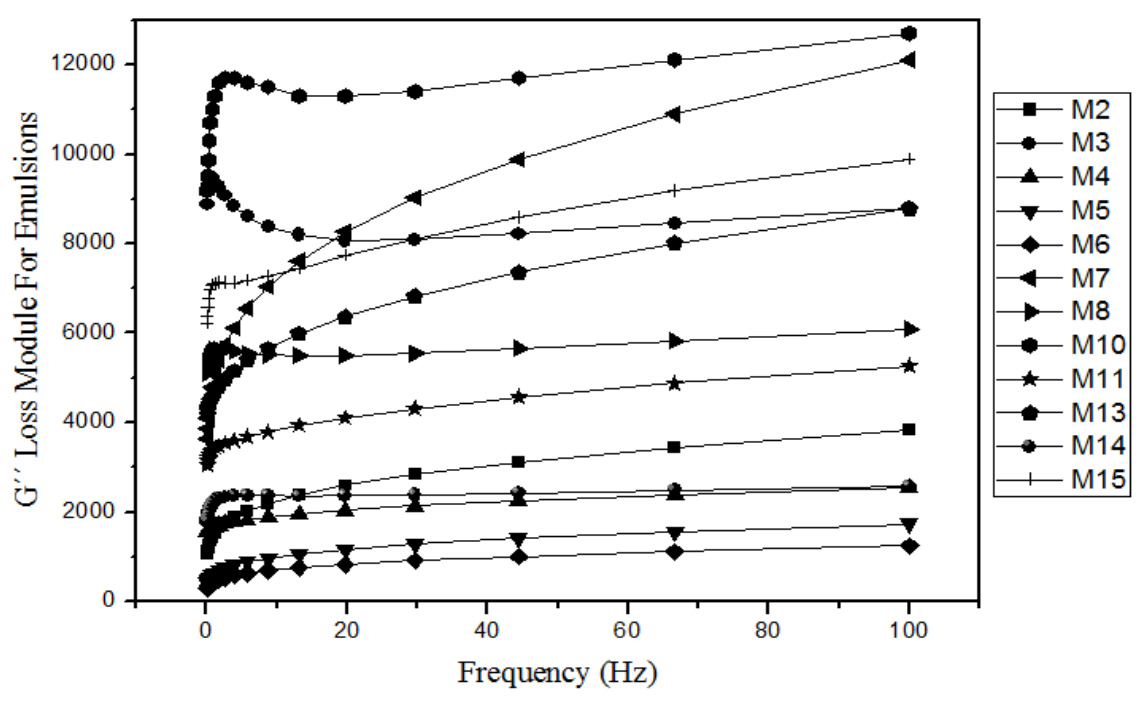

Fig. 3: G" loss module for emulsions formulated with quinoa and amaranth flours

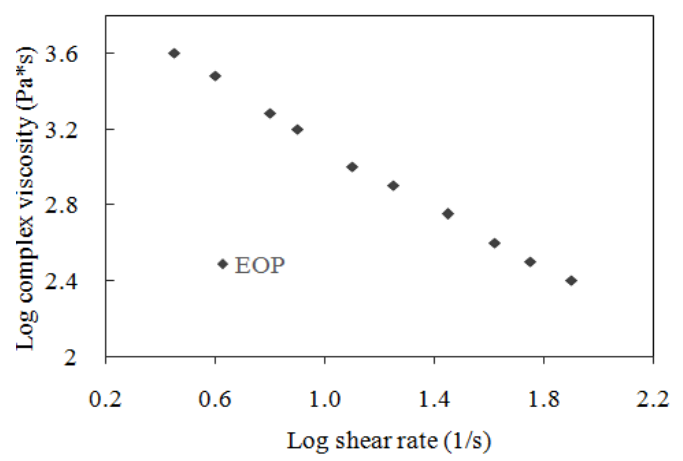

Fig. 4: Log complex viscosity $\left(\mathrm{Pa}^{*} \mathrm{~s}^{\mathrm{n}}\right)$ against $\log$ shear rate $(1 / \mathrm{sec})$ for the Optimized Emulsion (EOP)

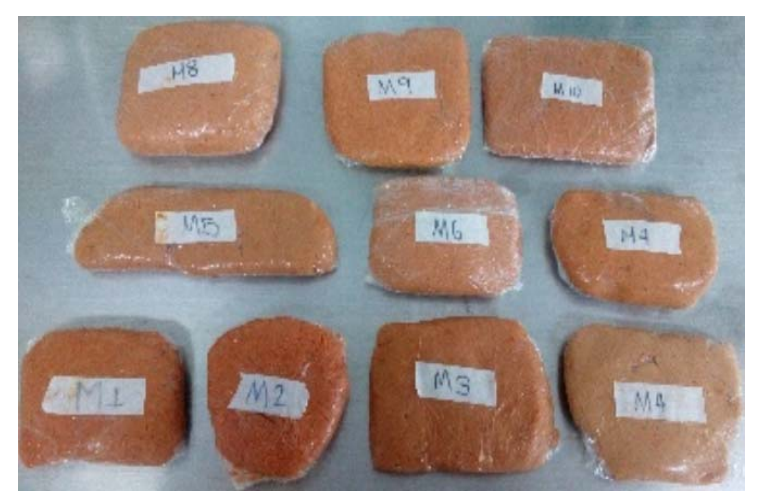

Fig. 5: Ham formulations from quinoa and amaranth

formulations were obtained, which were finally coldstored at $4^{\circ} \mathrm{C}$ for later characterization.

Color: Table 4 shows the color parameters $\mathrm{L}^{*}$, a* and $\mathrm{b}^{*}$ corresponding to the 10 Ham-Type Analog formulations (ATJ) of the optimum emulsion and to the two reference samples ATJC and JCC. The ANOVA
Table 4: Color parameters, CIEL* $a^{*} b^{*}$ scale for ATJ, ATJC and

\begin{tabular}{llll}
\multicolumn{1}{r}{ JCC } & & & \\
\hline Formulations & $\mathrm{L}^{*}$ & $\mathrm{a}^{*}$ & $\mathrm{~b}^{*}$ \\
\hline ATJ M1 & $0.83 \pm 0.21$ & $13.44 \pm 0.12$ & $26.09 \pm 0.24$ \\
ATJ M2 & $49.10 \pm 0.30$ & $17.04 \pm 0.19$ & $27.55 \pm 0.02$ \\
ATJ M3 & $49.90 \pm 0.03$ & $13.78 \pm 0.32$ & $25.45 \pm 0.23$ \\
ATJ M4 & $54.26 \pm 0.25$ & $10.45 \pm 0.14$ & $25.24 \pm 0.17$ \\
ATJ M5 & $51.57 \pm 0.21$ & $11.55 \pm 0.09$ & $25.09 \pm 0.16$ \\
ATJ M6 & $51.06 \pm 0.03$ & $15.20 \pm 0.18$ & $26.45 \pm 0.25$ \\
ATJ M7 & $50.85 \pm 0.08$ & $13.31 \pm 0.05$ & $25.82 \pm 0.15$ \\
ATJ M8 & $53.12 \pm 0.23$ & $11.98 \pm 0.21$ & $25.39 \pm 0.13$ \\
ATJ M9 & $50.83 \pm 0.15$ & $13.44 \pm 0.09$ & $26.09 \pm 0.22$ \\
ATJ M10 & $51.27 \pm 0.14$ & $13.48 \pm 0.06$ & $26.52 \pm 0.06$ \\
ATJC & $51.52 \pm 0.06$ & $14.35 \pm 0.21$ & $20.17 \pm 0.03$ \\
JCC & $55.52 \pm 0.2$ & $29.39 \pm 0.40$ & $9.73 \pm 0.04$ \\
\hline ATJ: & & &
\end{tabular}

ATJ: Ham-type analog formulations; ATJC: Commercial ham-type analog; JCC: Commercial cooked ham

indicated that no significant differences exist among the formulations or between this and ATJC; nevertheless, there are significant differences with respect to the with respect to JCC. However, this is not an inconvenience in the product's acceptance.

Texture: Table 5 presents the texture values corresponding to the 10 formulations of the Ham-Type Analog (ATJ) from the optimal emulsion and to two reference samples, ATJC and JCC. The ANOVA indicated significant differences among the 10 formulations and the reference samples in all texture parameters, except for the ATJ M8 formulation, which did not have significant differences with respect to the two reference samples with $\mathrm{p}<0.05$ in texture parameters of hardness, elasticity, gumminess and chewiness. Table 6 describes the ham-type analog ATJ M8 formulation.

Scanning Electron Microscopy (SEM): The scanning electron microscopy image shown on Fig. 6 allowed to identify in the optimized emulsion the formation of 
Adv. J. Food Sci. Technol., 16(SPL): 273-279, 2018

Table 5: Texture parameters for ATJ, ATJC and JCC

\begin{tabular}{lllll}
\hline Sample & Hardness & Elasticity & Gumminess & Chewiness \\
\hline ATJ M1 & $328 \pm 0.03$ & $0.76 \pm 0.09$ & $251 \pm 0.10$ & $231 \pm 0.22$ \\
ATJ M2 & $172 \pm 0.25$ & $0.81 \pm 0.04$ & $138 \pm 0.13$ & $127 \pm 0.01$ \\
ATJ M3 & $854 \pm 0.25$ & $0.89 \pm 0.19$ & $756 \pm 0.09$ & $708 \pm 0.12$ \\
ATJ M4 & $418 \pm 0.15$ & $0.81 \pm 0.09$ & $339 \pm 0.13$ & $310 \pm 0.14$ \\
ATJ M5 & $300 \pm 0.23$ & $0.84 \pm 0.25$ & $250 \pm 0.09$ & $232 \pm 0.15$ \\
ATJ M6 & $212 \pm 0.15$ & $0.85 \pm 0.23$ & $181 \pm 0.19$ & $167 \pm 0.09$ \\
ATJ M7 & $327 \pm 0.03$ & $0.77 \pm 0.15$ & $256 \pm 0.09$ & $240 \pm 0.25$ \\
ATJ M8 & $7334 \pm 0.10$ & $0.78 \pm 0.24$ & $1260 \pm 0.10$ & $946 \pm 0.09$ \\
ATJ M9 & $592 \pm 0.05$ & $0.74 \pm 0.21$ & $444 \pm 0.08$ & $417 \pm 0.22$ \\
ATJ M10 & $380 \pm 0.09$ & $0.84 \pm 0.25$ & $317 \pm 0.21$ & $298 \pm 0.17$ \\
ATJC & $7770 \pm 0.10$ & $0.18 \pm 0.52$ & $1413 \pm 0.30$ & $921 \pm 0.20$ \\
JCC & $8902 \pm 0.30$ & $0.39 \pm 0.12$ & $1790 \pm 0.10$ & $988 \pm 0.24$ \\
\hline ATJ
\end{tabular}

ATJ: Ham-type analog formulations; ATJC: Commercial ham-type analog; JCC: Commercial cooked ham

Table 6: Formulation of Ham-Type Analog (ATJ-M8)

\begin{tabular}{ll}
\hline ATJ M8 & $\mathrm{g} / \mathrm{kg}$ of emulsion $(\%)$ \\
\hline Textured soy & 20.0 \\
Paprika & 2.0 \\
Ham flavor & 5.0 \\
Preservative & 0.6 \\
\hline
\end{tabular}
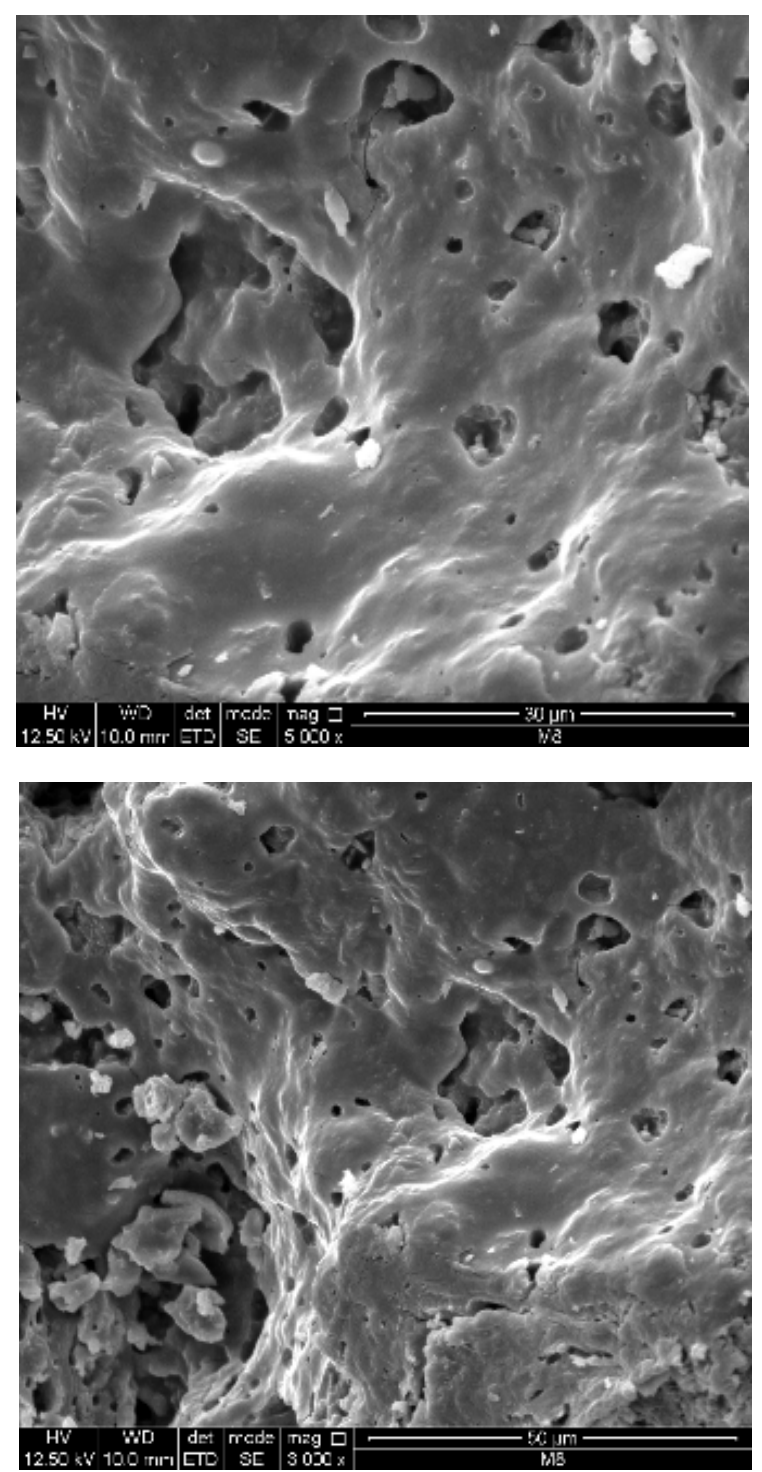

Fig. 6: SEM image to EOP (5000x-3000x) structures, where it can be observed a plastified surface characteristic of a gel, which indicates that there is an interaction between proteins, starch, fiber and fat; These interactions were propitiated by shearing and are in concordance with a viscoelastic behavior. Also there can be seen porosities that simulate the structure of muscle tissue that relates with the texturized soy protein used in the formula, allowing to obtain texture parameters similar to reference samples (ATJC y JCC) (Fang et al., 2014).

\section{CONCLUSION}

The response surface methodology permitted obtaining the best combination of factors, which consisted in a 1:1 ratio of quinoa flour and amaranth flour, hydration at 55 and $3 \%$ oil to potentiate the protein by $18.24 \%$, surpassing the levels required by Colombian norms for a Premium meat product $(15 \%)$. The extrusion process allowed obtaining an emulsion with characteristics suitable for the elaboration of a "ham-type" meat analog, finding that the mass exhibited pseudo-plastic behavior with $\mathrm{n}<1$. The TPA and color analyses enabled the selection of the formulation without significant differences with respect to the reference samples, finding that ATJ M8 complies with the color and texture characteristics of a commercial ham.

\section{ACKNOWLEDGMENT}

The authors thank the Interdisciplinary Institute of Sciences and the research vice-rector of the Universidad del Quindio, for the support received for the execution of this research.

\section{REFERENCES}

Asare, E.K., S. Sefa-Dedeh, E.O. Afoakwa, E. SakyiDawson and A.S. Budu, 2010. Modelling the effects of feed moisture and ingredient variations on the physical properties and functional characteristics of extruded sorghum-groundnutcowpea blends using response surface methodology. Int. J. Food Eng., 6(4): 1-17. 
Ayodele, I.F. and O.A. Aladesanmi, 2013. The proximate composition and sensory evaluation of the flours of breadfruit (Artocarpus altilis), benth seed (Adenopus breviflorus) and their composite bread. Chem. Mater. Res., 3(9).

Contreras-Jiménez, B., M. Gaytán-Martíne, E.M. Gutiérrez-Cortez and Valderrama-Bravo, 2017. Physicochemical and rheological characterization of opuntia ficus mucilage at three different maturity stages of cladode. Cereal Chem., 94(2): 230-236.

Fang, Y.Q., B. Zhang and Y.M. Wei, 2014. Effects of the specific mechanical energy on the physicochemical properties of texturized soy protein during high-moisture extrusion cooking. J Food Eng., 121(1): 32-38.

Filli, K.B., I. Nkama, U.M. Abubakar and V.A. Jideani, 2010. Influence of extrusion variables on some functional properties of extruded millet-soybean for the manufacture of 'fura': A Nigerian traditional food. Afr. J. Food Sci., 4(6): 342-352.

García-Salcedo, A.J., 2016. Caracterización y optimizacion de una mezcla de harina compuesta de quinua (Chenopodium quinoa) amaranto (Amaranthus caudatus) y chía (Salvia hispánica) para la formulación de analogos carnicos. M.S. Thesis, Quindio University, Colombia.
Juansang, J., C. Puttanlek, V. Rungsardthong, S. Puncha-Arnon and D. Uttapap, 2012. Effect of gelatinisation on slowly digestible starch and resistant starch of heat-moisture treated and chemically modified canna starches. Food Chem., 131(2): 500-507.

Omeire, G.C., M.O. Iwe and J.N. Nwosu, 2013. Influence of extrusion variables on the residence time and throughput of a single screw extruder. Brit. J. Appl. Sci. Technol., 3(2): 277-288.

Omohimi, C.I., O.P. Sobukola, K.O. Sarafadeen and L.O. Sanni, 2014. Effect of thermo-extrusion process parameters on selected quality attributes of meat analogue from mucuna bean seed flour. Niger. Food J., 32(1): 21-30.

Repo-Carrasco, R., C. Espinoza and S.E. Jacobsen, 2003. Nutritional value and use of the Andean crops quinoa (Chenopodium quinoa) and kañiwa (Chenopodium pallidicaule). Food Rev. Int., 19(12): 179-189.

Rumpold, B.A. and O.K. Schlüter, 2013. Potential and challenges of insects as an innovative source for food and feed production. Innov. Food Sci. Emerg., 17(1): 1-11.

Sandoval-Oliveros, M.R. and O. Paredes-Lopez, 2013. Isolation and characterization of proteins from chia seeds (Salvia hispanica L.). J. Agr. Food Chem., 61(1): 193-201. 